\title{
Avanços e desafios na formação do cirurgiấo-dentista para sua inserção nas práticas de promoção da saúde
}

\section{| ${ }^{1}$ Lucimeire de Sales Magalhães Brockveld, ${ }^{2}$ Sonia Isoyama Venancio |}

Resumo: A formação dos recursos humanos em saúde deve preparar um profissional para atuar multi- e interdisciplinarmente, de forma integral em todos os níveis de atenção. $\mathrm{O}$ objetivo desta pesquisa foi analisar avanços e desafios na formação do cirurgião-dentista após a promulgação das Diretrizes Curriculares Nacionais (DCN) no que diz respeito à promoção da saúde, focando a abordagem do aleitamento materno (AM) e alimentação complementar saudável (ACS). Utilizou-se pesquisa qualitativa, com análise documental dos projetos pedagógicos (PP), ementas e planos de ensino e entrevistas semiestruturadas com professores das disciplinas de Odontopediatria e Ortodontia de seis faculdades paulistas, de março a maio de 2018. As análises mostraram que os PP estão alinhados com as DCN, mas há pouca abordagem destinada ao AM e ACS como promotores de saúde bucal. $\mathrm{O}$ estudo concluiu que houve avanços na formação dos recursos humanos em saúde baseados em sólido arcabouço formado pela legislação brasileira. Há, no entanto, desafios a serem considerados, sendo necessário avançar no desenvolvimento de habilidades e competências preconizadas pelas DCN em temas que ampliem a promoção da saúde. As instituiçóes de ensino superior precisam favorecer que os PP se concretizem formando profissionais alinhados com suas propostas e as novas demandas do sistema de saúde.

> Palavras-chave: educação em odontologia; diretrizes curriculares nacionais; aleitamento materno; alimentação complementar saudável; promoção da saúde.

\author{
1 Universidade Cidade de São \\ Paulo. São Paulo-SP, Brasil \\ (lucimeirebrockveld@gmail.com). \\ ORCID: 0000-0002-0380-6291 \\ ${ }^{2}$ Instituto de Saúde. Secretaria de \\ Estado da Saúde de São Paulo. \\ São Paulo-SP, Brasil (sonia@ \\ isaude.sp.gov.br). \\ ORCID: 0000-0001-7147-3292
}

Recebido em: 15/06/2020

Aprovado em: 26/07/2020 Revisado em: 10/09/2020 


\section{Introdução}

A preocupação com a formação de recursos humanos em saúde tornou-se evidente por ocasião das discussôes da reforma sanitária que orientava um novo modelo de atençáo e um profissional de saúde que estivesse preparado para o novo desafio. A Constituiçẫo Brasileira de 1988 (BRASIL, 1988) garantiu o acesso universal às ações e serviços de saúde e atribui como uma das competências do Sistema Único de Saúde (SUS) a "ordenação da formação de recursos humanos na área de saúde", competência também expressa pela Lei no 8.080 (BRASIL, 1990). Para garantir um sistema de saúde público e de acesso universal, é necessário grande investimento na formação da força de trabalho em quantidade e qualidade (BRASIL, 2003a). A ampliação do acesso à saúde e a abertura de milhares de postos de trabalho no país trouxeram os desafios de provimento, fixação e qualificação dos trabalhadores do SUS. No que diz respeito à qualificação dos trabalhadores, o desafio é duplo: formar os futuros trabalhadores com competências, habilidades e atitudes voltadas às necessidades em saúde da população e qualificar as práticas dos trabalhadores em atuação a partir dos mesmos pressupostos.

No âmbito da educação, a Lei no 9.394/1996 estabeleceu a Lei de Diretrizes e Bases da Educação Nacional (LDBEN), definindo que "a educação escolar deverá vincular-se ao mundo do trabalho e à prática social” (BRASIL, 1996). Entre 2001 e 2002 foram aprovadas as diretrizes curriculares nacionais (DCN) para todos os cursos de graduação em saúde, buscando conceber a formação de nível superior como "um processo contínuo, autônomo e permanente, com uma sólida formação básica e profissional fundamentada na competência teórico-prática, de acordo com o perfil de um formando adaptável às novas e emergentes demandas"(BRASIL, 2003b).

Os pareceres de aprovação das DCN dos cursos de graduação da área da saúde fundamentaram-se nos documentos que regem a educação, mas também em documentos e legislação específicos da área da saúde. Segundo a respectiva área de conhecimento, contemplaram perfil do formando, competências, habilidades e atitudes, habilitaçôes, conteúdos curriculares, organização do curso, estágios e atividades complementares, flexibilizando o currículo e ampliando a autonomia das instituiçôes de ensino, ao contrário do que estabeleciam os currículos mínimos vigentes até então (BRASIL, 2001). 
A Resolução no CNS/CES/2002 (BRASIL, 2002), instituiu as Diretrizes Curriculares Nacionais (DCN) do Curso de Graduação de Odontologia, a serem observadas pelas instituiçóes de ensino superior (IES) para a construção curricular, e desde 2016 a Associação Brasileira de Ensino Odontológico (ABENO) vem conduzindo a discussão para atualização das diretrizes, sendo que uma versão preliminar foi aprovada pelo Conselho Nacional de Educação e aguarda a homologação do Ministro da Educação (Parecer CNE/CES no 803/2018) (BRASIL, 2018).

Desde 2004, com o lançamento, pelo Ministério da Saúde, da Política Nacional de Saúde Bucal - Brasil Sorridente -, a saúde bucal passou a ser ofertada de forma mais integral, com a inserção de procedimentos mais complexos na atenção básica $(\mathrm{AB})$ e a criação de uma rede de serviços de atenção em saúde bucal no SUS, ampliando o acesso aos serviços públicos odontológicos (BRASIL, 2004). Observamos ainda o significativo crescimento das equipes de saúde bucal, dos Centros de Especialidades Odontológicas (CEO), ampliação do acesso a água tratada e fluoretada, proporcionando uma melhoria das condiçôes de saúde bucal da população mais carente, elevando o Brasil ao grupo de países com baixa prevalência de cárie (PEREIRA, 2009).

No tópico referente à "Educação em Saúde", a PNSB destaca que a saúde bucal deve considerar tanto as diferenças sociais quanto as peculiaridades culturais, ao discutir alimentação saudável, manutenção da higiene e autocuidado do corpo, e orienta que os conteúdos sejam trabalhados de forma integrada com as demais áreas. É a $\mathrm{AB}$ o local privilegiado para as ações de promoção da saúde no tocante à promoção da amamentação e alimentação complementar saudável (ACS) e o cirurgiáo-dentista deve estar inserido nessas estratégias (BRASIL, 2006). No contexto da implantação do SUS, a promoção da saúde é uma estratégia de produção de saúde que contribui na construção de açóes que permitam responder às necessidades sociais em saúde e um dos eixos da Política Nacional de Promoção da Saúde (PNPS), em vigor desde 2006 e atualizada em 2015, é o incentivo à promoção da alimentação saudável (BRASIL, 2015).

Há evidências robustas dos aspectos preventivos da amamentação e da alimentação complementar (AC) oportuna em relação às estruturas e funçôes do sistema estomatognático (SE). A amamentação proporciona amadurecimento oral, pois estimula a tonicidade muscular e o desenvolvimento da articulação 
temporomandibular (ATM), promovendo, assim, espaço suficiente para a erupção dos dentes, melhorando seu posicionamento, o formato das arcadas e evitando problemas ortodônticos (CARVALHO, 2003). A maior duração da amamentação é fator de proteção contra a maloclusão inespecífica, bem como a mordida aberta anterior e a mordida cruzada posterior (PERES et al., 2015a). A maloclusão na dentição decídua pode ser preditiva também para a dentiçâo permanente, exercendo impactos negativos na vida dos adultos, relacionados à saúde bucal (PERES et al., 2015b).

A Organização Mundial da Saúde (OMS) e o Ministério da Saúde (MS) preconizam que, a partir dos seis meses, a criança comece a receber $\mathrm{AC}$ ao aleitamento materno (AM), que continua sendo importante fonte de calorias e nutrientes, embora sozinho, não supra as necessidades nutricionais do bebê (BRASIL, 2015; KRAMER; KAKUMA, 2002). Nessa idade a criança já apresenta maturidade fisiológica e neurológica para receber outros alimentos cuja trituração complementar é realizada pelas gengivas que já se encontram suficientemente endurecidas, em razão da aproximação dos dentes à superfície. Nesta fase, o desenvolvimento motor global oferece equilíbrio de cabeça e tronco, permitindo que ela permaneça sentada (DISHCHEKENIAN, 2013). A partir do surgimento dos primeiros dentes decíduos, a criança estará apta a realizar as funçôes de preensão e corte dos alimentos. Após a erupção dos molares decíduos, os alimentos duros, secos e fibrosos favorecem o desenvolvimento correto do SE (GUEDES-PINTO, 2010a).

Considerando o AM e AC como importantes na promoção da saúde e prevenção de doenças bucais, entre outros inúmeros benefícios (KRAMER, 2010; VICTORA et al., 2015; 2016), faz-se necessário conhecer as potencialidades e lacunas na atual formação do cirurgião-dentista após a promulgação das DCN sob o aspecto da promoção da saúde, focando o aprendizado do aleitamento materno e alimentação complementar saudável.

\section{Método}

Trata-se de uma pesquisa qualitativa, descritiva e interpretativa. A pesquisa qualitativa explora o universo dos significados, motivos, aspiraçôes, crenças, valores e atitudes, e adota uma abordagem naturalista e interpretativa para a compreensão do mundo social, para que seja possível entender e interpretar os fatos e os significados que as pessoas a eles conferem (DENZIN; LINCOLN, 2006; MINAYO, 2004). 
Para o estudo, foram selecionados seis cursos de Odontologia, sendo três de instituiçóes públicas (Faculdade de Odontologia de Araraquara da Universidade Paulista "Júlio de Mesquita Filho"/UNESP, Faculdade de Odontologia da Universidade de São Paulo/FOUSP e Faculdade de Odontologia de Piracicaba da Universidade Estadual de Campinas/FOP-UNICAMP) e três faculdades de instituiçôes privadas (Universidade Metodista de São Paulo /UMESP, Universidade Paulista/UNIP e Universidade Cidade de São Paulo/ UNICID). A escolha das faculdades teve como critérios de inclusão estarem ativas no cadastro do Ministério da Educação e estarem nas melhores posiçóes segundo a avaliação anual do ensino superior do Brasil, feito pela Folha de São Paulo. No ranking de universidades estão classificadas as 195 universidades brasileiras, públicas e privadas, a partir de cinco indicadores: pesquisa, internacionalização, inovação, ensino e mercado (FOLHA DE SÃO PAULO, 2017). O critério de exclusão foi a não resposta ao convite de seus representantes para participação no projeto.

A análise documental foi realizada nas matrizes curriculares inseridas nos projetos pedagógicos (PP) e nas ementas e planos de ensino das disciplinas de Odontopediatria e Ortodontia das faculdades selecionadas. Foram buscados o perfil do egresso e os temas destinados à prevenção/promoção da saúde através do aleitamento materno e alimentação complementar. A análise documental favorece a observação do processo de maturação ou de evolução de indivíduos, grupos, conceitos, conhecimentos, comportamentos, mentalidades, práticas, entre outros (CELLARD, 2008). A pesquisa dos documentos referente aos PP ocorreu nos portais das respectivas universidades e com os coordenadores dos cursos de Odontologia, para complementar as informaçôes.

O Projeto Político Pedagógico (PPP) está consolidado no artigo 12 na LDBEN (BRASIL, 1996), para que os estabelecimentos de ensino respeitem as normas comuns e as de seu sistema de ensino, tendo a missão de elaborar e executar sua proposta pedagógica e deve definir claramente o tipo de ação educativa que se quer realizar (VASCONCELLOS, 2000).

As entrevistas semiestruturadas foram realizadas individualmente com professores das disciplinas de Odontopediatria e Ortodontia das universidades selecionadas, entre os meses de março a maio de 2018. A entrevista semiestruturada permite interação e liberdade nos relatos dos informantes, valorizando a investigação, e resulta num complexo de dados, situaçóes, problemas, sentimentos e desejos, em um 
sistema de codificação, que se transformam em mensagens e sinais. É um sistema de transmissão que traduz a mensagem em significado (TRIVIÑOS, 1987).

Foram entrevistados 11 professores, sendo que uma professora de Odontopediatria é coordenadora em duas das universidades selecionadas. Entre os entrevistados, quatro eram do sexo masculino e sete do sexo feminino. A média de idade foi 56 anos, variando de 43 a 69 anos, o tempo médio de formado foi 34 anos, variando de 18 a 44 anos, e o tempo médio atuando na docência foi 26 anos, variando de 11 a 39 anos.

Para a análise dos dados, cinco categorias temáticas foram previamente selecionadas, a partir das recomendações das DCN, especialmente no que tange à orientação para a promoção da saúde e prevenção das doenças, delineando o roteiro para o desenvolvimento da pesquisa. Os entrevistados assinaram o Termo de Consentimento Livre e Esclarecido, sendo previamente informados sobre os objetivos e métodos do estudo. Como forma de manter o sigilo da identificação, os professores são apresentados a partir de codinomes (P1, P2, P3...).

O estudo teve aprovação do Comitê de Ética e Pesquisa da Faculdade de Saúde Pública da Universidade de São Paulo - FSP/USP (CAAE: 80436217.4.0000.5421).

\section{Resultados e Discussão}

\section{Consonância do currículo com as DCN}

Todas as faculdades pesquisadas tiveram seus PP revistos e construídos após as orientaçôes das DCN de 2002. Alguns documentos trazem explicitamente a preocupação para a adequação dos currículos para que respondam às novas necessidades pedagógicas na formação do aluno.

A Faculdade de Odontologia de Araraquara implantou seu PP em 2006 e fez uma reestruturação curricular com a elaboração de competências esperadas para cada ano da graduação, norteado pelas DCN, em 2008 (UNESP, 2016). O curso de graduação de Odontologia da Faculdade de Odontologia da Universidade de São Paulo conduziu uma reestruturaçáo curricular a partir de 2005. Buscou atender às DCN e a reorientação da formação profissional proposta pelo Programa Nacional de Reorientação da Formação Profissional em Saúde (Pró-Saúde) (HADDAD et al., 2018; USP, 2018). A Faculdade de Odontologia de Piracicaba tem uma nova estrutura curricular a partir de 2012, com uma organização modular do currículo (UNICAMP, 2015). O PP da Universidade Cidade de São Paulo (UNICID, 2012) não aborda o processo de construçáo da matriz curricular, estando no momento 
da pesquisa em reestruturação segundo a coordenação do curso. Para confecção da matriz curricular da Universidade Metodista de São Paulo (UMESP, 2019) foram observados vários documentos ministeriais ligados ao assunto, bem como a participação do corpo docente, discente, técnico-administrativo e da comunidade. No site da Universidade Paulista (UNIP, 2019), encontramos o PP bem resumido. No item "grade curricular", encontramos apenas a lista de disciplinas, sem as ementas ou conteúdos programáticos.

Com alguma variação no texto, todas as faculdades analisadas acompanham o perfil do formando egresso/profissional previsto nas DCN. Os PP analisados detalham o que esperam de seus alunos e incluem palavras que mostram a preocupação com a formação para a promoção de saúde: capazes de atuar em todos os níveis de atenção à saúde (promoção, prevenção e reabilitação), individual e coletivamente (UNESP, 2016); que faça da promoção da saúde o eixo condutor de sua prática profissional (USP, 2018); educar o paciente e a comunidade visando a melhoria e manutenção da saúde bucal e aplicar métodos preventivos em nível individual ou coletivo (UNICAMP, 2015); formar o aluno com a consciência de prevenir as afecções do aparelho estomatognático, com capacidade de atuação crítica no gerenciamento dos serviços de saúde comunitária (UNICID, 2012); atuar em todos os níveis de atenção à saúde, integrando-se em programas de promoção, manutenção, prevenção e recuperação da saúde, sensibilizados e comprometidos com o ser humano, respeitando-o e valorizando-o (UMESP, 2019); tornar o estudante um promotor de saúde, atuando na prevenção e controle das doenças (UNIP, 2019).

Nesta primeira categoria, os professores participantes convergentemente responderam com mais ou menos ênfase que o currículo acompanha o que prevê as DCN.

Sim, com certeza. [...] O aluno aqui é preparado para ser um dentista generalista, e sempre a parte preventiva é enfocada. (P3)

Nós realmente temos nossa disciplina voltada para prevenção assim como para o tratamento. Dentro da odontopediatria nós temos disciplinas voltadas para a prevenção, açôes preventivas, nós temos um serviço de atendimento extramuro onde nós fazemos todo esse trabalho. (P4)

Sim, a gente trabalha em cima disso (das DCN), inclusive. Trabalha com filosofia minimamente invasiva. (P5)

É garantida a preocupação com a prevenção e promoção da saúde, mas com uma visão voltada para a ortodontia, para os eventuais possíveis problemas ortodônticos. (P11) 


\section{Formação atual do aluno de graduação, em comparação com a formaçáo antes das DCN}

Os professores relatam a mudança no currículo após a promulgação das $\mathrm{DCN}$, principalmente em relação ao ensino da promoção da saúde.

Muita diferença. Na parte ortodôntica, a gente nem falava em prevenção. Era só a intervenção mesmo. (P7)

Muita, muita diferença. Se discute tanto na saúde coletiva na minha escola, como na odontopediatria o conceito de prevenção e promoção de saúde, a importância disso na melhoria da população. Na nossa formação era totalmente uma odontologia curativa. (P2)

Um professor expressou a mudança como negativa, diminuindo a carga horária destinada a conteúdos importantes.

Sim. Muda porque a gente náo pode deixar de acompanhar o desenvolvimento científico e tecnológico. Na vida escolar, estudantil, diminuiu muito o tempo. A parte de ensino em si, ficou bastante resumida. Ficou restrito. Porque tem outras disciplinas encaixando. A parte do crescimento, por exemplo, a gente dava um semestre inteiro. Crescimento e desenvolvimento. Hoje damos em 2 meses. Então diminuiu bastante. (P8)

Diversos países com diferentes contextos socioeconômicos e culturais tem realizado mudanças curriculares em Odontologia nas últimas décadas (LOOMER et al., 2012; MURTOMAA, 2009). No Brasil, o Conselho Federal de Educação (BRASIL, 1982) estabeleceu a formação de um profissional generalista e estabeleceu o currículo mínimo dos cursos de Odontologia que foi a base para seu ensino no país, e exerceu influência sobre o que se observa ainda hoje em muitos cursos, como essencial para a formação superior da profissão. Somente a partir da aprovação da LDBEN (BRASIL, 1996) e posterior aprovação das DCN (BRASIL, 2002), novos parâmetros foram apresentados e sinalizaram a necessidade de maior interação entre ensino, serviço e comunidade (MORITA; KRIGER, 2004).

$\mathrm{O}$ incentivo às mudanças curriculares para formar recursos humanos para $\mathrm{O}$ SUS foi inicialmente dado pelo Ministério da Saúde para os cursos de Medicina. Em 2005, o programa foi ampliado e denominado Pró-Saúde, surgindo então as primeiras reformas curriculares direcionando a formação do cirurgião-dentista para uma atuação mais específica para a atenção básica $(\mathrm{AB})$, especialmente a Estratégia de Saúde da Família (ESF) e suas necessidades (BRASIL, 2009).

No entanto, apesar dos esforços para a adequação do currículo, existe uma distância entre a proposta e a prática da formação e no caso da Odontologia. Zilbovicius (2007) conclui que o currículo oculto hegemônico (o que é realmente 
desenvolvido) continua a ser o de caráter tecnicista, flexneriano e na contramão dos objetivos do Pró-Saúde e das próprias DCN. Ao contrário, espera-se que os cursos capacitem os profissionais para enfrentar os problemas do processo saúde/doença da populaçấo, respeitando os princípios do SUS e atuando com responsabilidade integral sobre a população brasileira, em consonância com as DCN.

\section{Problemas bucais que recebem maior ênfase na prevenção}

Os programas e ementas analisados enfatizam que as disciplinas não devam ser especialidades isoladas, mas sim uma necessidade para a promoção da saúde bucal da população. Destacam o papel da Odontologia preventiva na infância visando à obtenção da saúde bucal plena na idade adulta e mencionam sobretudo a prevenção da cárie dental, doença periodontal e a prevenção das maloclusões.

A prioridade desses temas foi consenso entre os professores entrevistados. A grande preocupação das disciplinas com o conteúdo sobre a etiologia e a prevenção da doença cárie se justifica por ser a patologia mais prevalente na população, embora esta realidade esteja sendo alterada por diversas açóes conjuntas, mostrando um histórico positivo com grandes avanços no seu controle. De acordo com a Pesquisa Nacional de Saúde Bucal 2010 (BRASIL, 2012), conhecida como Projeto SB Brasil 2010, o índice CPO aos 12 anos foi 2,07. ${ }^{1}$ No primeiro inquérito nacional, realizado em 1986, o índice foi de 6,7, e em 2003 foi de 2,78, havendo, portanto, uma redução significativa. Na dentiçáo decídua, o ataque de cárie em crianças de cinco anos foi, em média, de 2,43 dentes, 13,9\% menor do que em 2003, quando a média foi de 2,8 dentes afetados.

O mesmo estudo apresenta os resultados das condiçôes oclusais nas idades de 5-12 anos e na faixa etária de 15-19 anos para o Brasil e regióes. Os dados mostram que aos cinco anos foram encontrados $23 \%$ de crianças com alguma alteração oclusal, e aos 12 anos, 40\%. A mordida aberta anterior, alteração provocada pelo uso de bicos e chupetas, afetou $12,1 \%$ dos jovens.

Guedes-Pinto (2010b) afirma que os aspectos preventivos não constituem um aspecto isolado na Odontologia, limitado, por exemplo, ao ensinamento dos procedimentos de higiene bucal, conselhos sobre dieta e aplicação de flúor, mas devem envolver os aspectos individuais e familiares, focando numa compreensão mais integral do paciente. Portanto, programas mais integrados e abrangentes podem 
levar ao entendimento do papel do dentista na promoção do AM e AC, ampliando o conceito de prevençáo e promoção da saúde, incorporando novos saberes e atitudes.

\section{Presença do ensino relacionado ao aleitamento materno na grade curricular}

Não consta em nenhuma ementa ou plano de ensino dessas disciplinas as palavras “amamentação/aleitamento materno". Não há menção ao ensino da prevenção de doenças ou promoção da saúde geral ou bucal pela prática do aleitamento materno.

As falas dos professores complementam as informaçóes sobre o pouco conteúdo do tema abordado. Com algumas exceçôes, a maioria, apesar de saber a importância do AM e AC no desenvolvimento do SE, admite que a carga horária oferecida para estes assuntos é insatisfatória.

Não. Eu não tenho uma discussão focada no aleitamento materno. $\mathrm{O}$ aleitamento materno vai entrar assim: ele pode ajudar a prevenir cárie, ele pode ajudar a prevenir a maloclusão, ele deve ser incentivado, mas assim... nós não fazemos uma abordagem teórica do aleitamento materno, sobre todos os aspectos, né? Da sua importância, o que ele previne, como ele deve ser feito, como ele deve ser estimulado, nada disso. (P1)

Não. Eu acho que deveria ser discutido sim, porque se nós falamos sobre crescimento e desenvolvimento, se o AM contribui para um correto ou melhor desenvolvimento da face, acho que deveria sim. (P11)

Muito pouco. Ele entra quando nós ministramos a aula de hábitos deletérios: chupeta, sucçấo não nutritiva. É mais vinculado à parte ortodôntica do processo. Não existe um momento aleitamento materno. (P2)

Sim. Mas consigo falar 10, 15 minutos sobre aleitamento. Não dá para sensibilizar. A informação é apresentada, colocada. Na prática, vou ter isso abordado na aula de etiologia, vai voltar na aula de oclusóes transversais e mordida cruzada e vai voltar na aula de mordida aberta. Mas sempre pincelado. (P9)

Algumas falas, no entanto, expressam opinióes de professores que acham adequado/suficiente a grade destinada ao tema.

Sim, é discutido. Está diluído na carga horária. Acho suficiente. Eu vejo que os alunos têm conhecimento. (P3)

Ele é tratado, mas não tem nenhuma aula específica com o tema aleitamento materno. Ele é tratado dentro das aulas de prevenção. [...] eu penso assim, que a nossa função é formar o clínico com noçóes gerais de tudo um pouquinho, para ele saber encaminhar o paciente, saber orientar. (P4)

Sim, prevenção de respirador bucal e maloclusões. [...] A gente dá uma boa noção para eles aplicarem. (P10) 
A prevenção de distúrbios do aparelho estomatognático é eficaz através da prática do AM e pode provocar mudanças nos resultados de condições bucais adversas, como cárie e problemas oclusais. Dados da II Pesquisa de Prevalência de Aleitamento Materno (II PPAM) apontaram que o consumo de bebidas e alimentos adoçados era menor entre os lactentes amamentados, o que levaria à uma diminuição da incidência de cárie (PASSANHA; BENÍCIO; VENÂNCIO, 2018).

Após verificarem que a prevalência dos problemas oclusais aumenta na dentição permanente em relação à dentição decídua, Frazão e colaboradores recomendam que atividades específicas de proteção nos programas materno-infantis voltados para o desenvolvimento de crianças de 0-6 anos sejam adotadas nos sistemas de saúde locais. Entre os fatores associados à maloclusão, apontam os curtos períodos de amamentação, perda precoce de dentes, doenças respiratórias e hábitos deletérios de sucção. Acrescentam que métodos de intervenção devam ser investigados e implantados para reduzir as maloclusão moderada/grave para níveis socialmente mais aceitáveis e economicamente mais sustentáveis (FRAZÃO et al., 2004).

Bönecker, Modesto e Walter (2010) argumentam que os problemas de saúde bucal ainda são muitas vezes vistos dissociados da saúde geral, mas que quando não adequadamente prevenidos ou trabalhados, além da dor e desconforto, interferem nas dimensões biopsicossociais.

\section{Presença do ensino relacionado à alimentação complementar saudável na grade curricular}

Náo consta em nenhuma ementa ou plano de ensino dessas disciplinas a expressão "alimentação complementar". Não há menção ao ensino da prevenção de doenças ou promoção da saúde geral ou bucal pela orientação a uma alimentação complementar saudável.

$\mathrm{Na}$ análise das falas, fica evidente que o tema da alimentação saudável é abordado nas aulas com a intenção de falar da relação da ingestão do açúcar e doenças como cárie, sobretudo na disciplina de Odontopediatria. Novamente, não há consenso entre os professores sobre a adequação do tema na grade curricular.

Aí a gente tem uma aula específica sobre hábitos alimentares. Mas o foco do hábito alimentar é exatamente a relação do açúcar [...] é muito voltado para cárie. Não tem abordagem de crescimento e desenvolvimento não. (P1) 


\begin{abstract}
A gente repete duas vezes esta aula. [...] Tem que dar alimentação dura, tudo para ter um melhor desenvolvimento. $\mathrm{Na}$ fase de erupção do dente, nós damos a cronologia da erupçáo dos dentes, desde a formaçấo, a odontogênese. Conforme a erupção dos dentes, a gente vai falando que tipo de mastigação está tendo. (P5)

Não, na ortodontia, não. Normalmente a odontopediatria que daria esta parte. (P10)

Sim, com certeza. Eu ministro aula aqui há 30 anos, numa situação de integração com todas as disciplinas, não só na pediatria. Eu posso te garantir que sim. (P12)
\end{abstract}

As DCN (BRASIL, 2002) ressaltam que o curso de graduação em Odontologia deve assegurar a formação de profissionais com competências e habilidades específicas para, entre outras questôes, atuar em todos os níveis de atenção à saúde, integrandose em programas de promoção, manutenção, prevenção, proteção e recuperação da saúde, sensibilizados e comprometidos com o ser humano, respeitando-o e valorizando-o. Sinalizam uma mudança de paradigma formando um profissional crítico, atento à sua realidade social e preparado para trabalhar em equipe.

A formação dos hábitos alimentares saudáveis na primeira infância é estratégia fundamental para o bom desenvolvimento da criança, prevenção de obesidade e de outras doenças crônicas na vida adulta (PERRINE et al., 2014), sendo fundamental a formação do dentista para se inserir em açôes de promoção da ACS.

A formação do cirurgião-dentista deve capacitá-lo a executar ações de promoção, prevenção e proteção da saúde, bem como propiciar sua liderança e coordenação de uma equipe de saúde, baseado nos pressupostos de uma educação sintonizada com as transformaçôes sociais e epidemiológicas da população (HADDAD et al., 2006).

Embora o objetivo da graduação seja a formação do cirurgiáo-dentista generalista, $30 \%$ dos egressos vão para o setor público incorporar-se em equipes de Saúde da Família, na AB (RIZZO, 2018). O eixo do currículo odontológico, incluindo as ações de promoção da saúde bucal, de prevenção e reabilitação, deve ser o processo saúde-doença e as necessidades sentidas pela população. Isto implica interação, e não compartimentação de saberes, que incentiva especializaçóes precoces, voltadas mais a suprir um nicho de mercado do que a própria saúde bucal (SAN MARTIN, 2018).

Esta pesquisa apresenta limitaçóes, ao analisar poucas faculdades paulistas, considerando que de 2015 a 2019, o número de faculdades de Odontologia no Brasil passou de 220 para 412 (CFO, 2019). No entanto, as faculdades analisadas são as mais bem avaliadas segundo indicadores importantes. Estudos mais abrangentes podem ampliar a discussão e o debate proposto. 


\section{Conclusão}

O estudo concluiu que houve grandes avanços na formação dos recursos humanos em saúde baseados em sólido arcabouço formado principalmente pelas DCN, diretrizes e princípios do SUS, a PNSB e a PNPS, entre outras conquistas. Há, porém, desafios a serem considerados, sendo necessário avançar no desenvolvimento de habilidades e competências preconizadas pelas DCN em temas que ampliem a promoção da saúde e a prevenção de doenças, contemplando os interesses do SUS, compatibilizando e valorizando as necessidades sentidas pela população e pelos profissionais de saúde. As instituiçôes de ensino superior precisam favorecer que de fato seus PP se concretizem e formem profissionais alinhados com suas propostas e as novas demandas do sistema de saúde. ${ }^{2}$

\section{Referências}

BÖNECKER, M. J. S.; MODESTO, A.; WALTER, L. R. F. Programas de atenção odontológicas para bebês, crianças e adolescentes. In: MASSARA, M. L. A.; RÉDUA, P. C. B. (Orgs.). Manual de referência para procedimentos clínicos em Odontopediatria. São Paulo: Santos, 2010. p. 9-13.

BRASIL. Lei no 8.080, de 19 de setembro de 1990. Dispóe sobre as condiçóes para a promoção, proteção e recuperação da saúde, a organização e o funcionamento dos serviços correspondentes e dá outras providências. Diário Oficial [da] República Federativa do Brasil, seção 1, Brasília, DF, ano 128, n. 182, p. 18055, 20 set. 1990.

. Lei no. 9.394, de 20 de dezembro de 1996. Estabelece as Diretrizes e Bases da Educaçấo Nacional. Diário Oficial [da] República Federativa do Brasil, seçấo 1, Brasília, DF, ano 134, n. 248, p. 27833-27841, 23 dez. 1996.

. Ministério da Educação. Conselho Federal de Educação, Resolução no 04/82. Diário Oficial da União. Brasília, 16 set. 1982.

Ministério da Educação. Conselho Nacional de Educação. Câmara de Ensino Superior. Parecer CNS/CES no 1300/2001 de 7 de dezembro de 2001. Dispóe sobre as Diretrizes Curriculares Nacionais dos Cursos de Graduação em Farmácia e Odontologia. Diário Oficial da Uniāo, seção 1, Brasília, DF, ano 138, n. 233, p. 25, 7 dez. 2001.

. Ministério da Educação. Conselho Nacional de Educação. Câmara de Educação Superior. Resolução no CNE-CES 3, de 19 de fevereiro de 2002. Institui as Diretrizes Curriculares Nacionais do Curso de Graduação em Odontologia. Diário Oficial da União, seçâo 1, Brasília, DF, ano 139, n. 42, p. 10, 4 mar. 2002. 
- Ministério da Educação. Conselho Nacional de Educação. Câmara de Ensino Superior. Parecer CNS/CES ño 67, de 11 de março de 2003b. Dispóe sobre o Referencial para as Diretrizes Curriculares Nacionais - DCN dos Cursos de Graduação. Brasília, DF: MEC, [2003b]. Disponível em: <http://portal.mec.gov.br/cne/arquivos/pdf/CES0067.pdf>. Acesso em: 6 maio 2019.

- Ministério da Educação. Conselho Nacional de Educação. Câmara de Educação Superior. Parecer CNE/CES no 803/2018. Aguarda homologação do Ministro da Educação Disponível em: <http://portal.mec.gov.br/docman/abril-2019-pdf/111231-18/file>. Acesso em: 26 dez. 19.

- Ministério da Saúde. Portaria no 648, de 28 de março de 2006. Aprova a Política Nacional de Atenção Básica, estabelecendo a revisão de diretrizes e normas para a organizaçáo da Atenção Básica para o Programa Saúde da Família (PSF) e o Programa Agentes Comunitários de Saúde (PACS). Brasília: MS, 2006.

. Ministério da Saúde. Secretaria de Atenção à Saúde. Departamento de Atenção Básica. Coordenação Nacional de Saúde Bucal. Diretrizes da política nacional de saúde bucal. Brasília: MS, 2004.

. Ministério da Saúde. Secretaria de Atenção à Saúde. Departamento de Atenção Básica. Saúde da criança: aleitamento materno e alimentação complementar. 2. ed. Brasília: MS, 2015. (Caderno de Atenção Básica, n. 23).

. Ministério da Saúde. Secretaria de Atenção à Saúde. Secretaria de Vigilância em Saúde. SB Brasil 2010: Pesquisa Nacional de Saúde Bucal: resultados principais. Brasília: Ministério da Saúde, 2012.

. Ministério da Saúde. Secretaria de Políticas de Saúde. Coordenação-Geral da Política de Recursos Humanos. Política de recursos humanos para o SUS: balanço e perspectivas. Brasília: Ministério da Saúde, 2003a. (Série C. Projetos, Programas e Relatórios).

- Ministério da Saúde. Secretaria de Vigilância em Saúde. Secretaria de Atenção à Saúde. Política Nacional de Promoção da Saúde: PNPS: revisão da Portaria MS/GM no 687, de 30 de março de 2006. Brasília: MS, 2015.

- Ministério da Saúde; Ministério da Educação. Programa Nacional de Reorientação da Formação Profissional em Saúde - PRÓ-SAÚDE: objetivos, implementação e desafios profissionais. Brasília-DF: MS/MEC, 2009. (Série C. Projetos, Programas e Relatórios).

BRASIL. Senado Federal. Constituição da República Federativa do Brasil. Brasília: Senado Federal, 1988.

CONSELHO FEDERAL DE ODONTOLOGIA. Disponível em: http//cfo.org.br. Acesso em: 03 jan. 20. 
CARVALHO, G. D. O sistema estomatognático e suas funções. In: S.O.S. respirador bucal: uma visão funcional e clínica da amamentação. São Paulo: LOVISE, 2003. p. 27-56.

CELLARD, A. A análise documental. In: POUPART, J. et al. A pesquisa qualitativa: enfoques epistemológicos e metodológicos. Petrópolis: Vozes, 2008. p. 295-316.

DENZIN, N. K.; LINCOLN, Y. S. O planejamento da pesquisa qualitativa: teorias e abordagens. Porto Alegre: Artmed, 2006.

DISHCHEKENIAN, V. R. M. et al. Nutrição: sua importância no crescimento e desenvolvimento orofacial. In: COUTINHO, L.; BÖNECKER, M. (Orgs.). Odontopediatria para o pediatra. São Paulo: Atheneu, 2013. p. 90-98. (Série Atualizaçóes Pediátricas).

FRAZÃO, P. et al. Má oclusão severa é mais frequente na dentição permanente do que na decídua? Rev. Saúde Pública, São Paulo, v. 38, n. 2, p. 247-254, 2004.

FOLHA DE SÃO PAULO. Ranking Universitário de Odontologia. Disponível em: https://ruf. folha.uol.com.br/2017/ranking-de-cursos/odontologia. Acesso em 30 jun. 17.

GUEDES-PINTO, A. C. Odontopediatria. 8. ed. Fatores Pós-natais de Interesse para a Ortodontia Preventiva. São Paulo: Santos, 2010a. p. 833-840.

GUEDES-PINTO, A. C. Odontopediatria. 8. ed. Educação do Paciente em Odontopediatria. São Paulo: Santos, 2010b. p. 399-416.

HADDAD, A. E. et al. (Orgs.). A trajetória dos cursos de graduação na saúde: 1991-2004. Brasília: INEP, 2006.

HADDAD, A. E. et al. A Política Nacional de Educação Superior na Saúde e a reorientação curricular da FOUSP: análise comparativa do desempenho e percepção dos estudantes. Grad+ Rev. Grad. USP, v. 3, n. 2, p. 15-23, jul. 2018.

KRAMER, M. S. "Breast is best": the evidence. Early Hum. Dev., v. 86, n. 11, p. 729-732, nov. 2010.

KRAMER, M. S.; KAKUMA, R. The optimal duration of exclusive breastfeeding: a systematic review. Geneva: WHO, 2002. Disponível em: https://www.who.int/nutrition/publications/ optimal_duration_of_exc_bfeeding_review_eng.pdf. Acesso em: 15 maio 2019.

LOOMER, P. M. et al. New curriculum in dentistry for Tanzania: competency-based education for patient and population health (2008-2011). J. Public Health Policy, v. 33, suppl. 1, p. S92-S109, 2012.

MINAYO, M. C. S. (Org.). Pesquisa social: teoria, método e criatividade. 23. ed. Petrópolis: Vozes; 2004.

MORITA, M. C.; KRIGER, L. Mudanças nos cursos de Odontologia e a interação com o SUS. Rev. ABENO, Londrina, v. 4, n. 1, p. 17-21, 2004. 
MURTOMAA, H. Dental education in Europe. Eur. J. Dent., v. 3, n. 1, p. 1-2, jan. 2009.

PASSANHA, A.; BENÍCIO, M. H. D.; VENÂNCIO, S. I. Influência do aleitamento materno sobre o consumo de bebidas ou alimentos adoçados. Rev. Paul. Pediatr., São Paulo, v. 36, n. 2 , p. $148-154,2018$.

PEREIRA, A. C. Tratado de Saúde Coletiva em Odontologia. Nova Odessa: Napoleão, 2009.

PERES, K. G. et al. Deciduous-dentition malocclusion predicts orthodontic treatment needs later: findings from a population-based birth cohort study. Am. J. Orthod. Dentofacial Orthop., v. 147, n. 4, p. 492-498, Apr. 2015 b.

. Effect of breastfeeding on malocclusions: a systematic review and meta-analysis. Acta Paediatr., v. 104, n. 467, p. 54-61, Dec. 2015a.

PERRINE, C. G. et al. Breastfeeding duration is associated with child diet at 6 years. Pediatrics, v. 134, suppl. 1, p. S50-S55, Sep. 2014.

RIZZO, H. G. M. Características da força de trabalho dos cirurgióes-dentistas no Brasil. 2018. Dissertação (Mestrado em Ciências Odontológicas) - Faculdade de Odontologia, Universidade de São Paulo, São Paulo, 2018.

SAN MARTIN, A. S. et al. Distribuição dos cursos de odontologia e de cirurgióes-dentistas no Brasil: uma visão do mercado de trabalho. Rev. ABENO, Londrina, v. 18, n. 1, p. 63-73, 2018.

TRIVIÑOS, A. N. S. Introdução à pesquisa qualitativa em educação. São Paulo: Atlas, 1987.

UNIVERSIDADE CIDADE DE SÃO PAULO. Odontologia: projeto pedagógico do curso (PPC). São Paulo: UNICID, 2012.

UNIVERSIDADE DE SÃO PAULO. Faculdade de Odontologia. Projeto pedagógico do Curso de Odontologia da Faculdade de Odontologia da Universidade de São Paulo. São Paulo: FOUSP, 2018. Disponível em: http://www.fo.usp.br/wp-content/uploads/Projeto-Pedagogico-FOUSP2018-a.pdf. Acesso em: 10 jun. 2019.

UNIVERSIDADE ESTADUAL DE CAMPINAS. Faculdade de Odontologia de Piracicaba. Projeto pedagógico: FOP Unicamp. Piracicaba: Unicamp/FOP, 2015. Disponível em: https:// www.fop.unicamp.br/ccg/index.php/o-curso/projeto-pedagogico. Acesso em: 10 jun. 2019.

UNIVERSIDADE ESTADUAL PAULISTA “JÚLIO DE MESQUITA FILHO”. Faculdade de Odontologia de Araraquara. Projeto pedagógico. Araraquara: UNESP, 2016. Disponível em: https://www.foar.unesp.br/Home/Graduacao/projeto-politico-pedagogico-3816.pdf. Acesso em: 10 jun. 2019.

UNIVERSIDADE METODISTA DE SÃO PAULO. Projeto Pedagógico do curso de Odontologia. São Bernardo: Metodista, 2019. Disponível em: http://portal.metodista.br/odontologia/ppc/ projetopedagogicodocurso.pdf. Acesso em: 10 jun. 2019. 
UNIVERSIDADE PAULISTA. Projeto pedagógico do curso (PPC): Odontologia. [2019?]. Disponível em: https://www.unip.br/presencial/ensino/graduacao/tradicionais/bio_ odontologia.aspx. Acesso em: 10 jun. 2019.

VASCONCELLOS, C. S. Planejamento: Projeto de ensino-aprendizagem e projeto político pedagógico. 9. ed. São Paulo: Libertad, 2000.

VICTORA, C. G. et al. Association between breastfeeding and intelligence, educational attainment, and income at 30 years of age: a prospective birth cohort study from Brazil. Lancet Glob. Health, v. 3, n. 4, p. e199-e205, Apr. 2015.

. Breastfeeding in the 21st century: epidemiology, mechanisms, and lifelong effect. Lancet, v. 387, n. 10017, p. 475-90, Jan 2016.

ZILBOVICIUS, C. Implantação das diretrizes curriculares para cursos de Graduação em Odontologia no Brasil: contradiçóes e perspectivas. 2007. Tese (Doutorado em Ciências Odontológicas) - Faculdade de Odontologia, Universidade de São Paulo, São Paulo, 2007.

\section{Notas}

${ }^{1} \mathrm{O}$ índice CPO é um indicador de dentes cariados, perdidos e obturados. Devido ao seu caráter cumulativo ao longo dos anos, é sempre referido em relação à idade. Um indicador utilizado internacionalmente é o CPO aos 12 anos, pois reflete o ataque de cárie logo no começo da dentição permanente.

${ }^{2}$ L. de S. M. Brockveld: elaboração e delineamento do estudo, pesquisa, coleta de dados, análise e interpretação dos dados, redação do artigo. S. I. Venancio: orientou a elaboração e delineamento do estudo, análise e interpretação dos dados, redação e revisão do artigo. 


\section{Abstract}

Advances and challenges in training the

dentist for its insertion in health promotion practices

The training of human resources in health should prepare a professional to act multi- and interdisciplinarily, in a comprehensive manner at all levels of care. This worked aimed to analyze advances and challenges in the training of dentists after the promulgation of the National Curricular Guidelines (NCG) regarding health promotion, focusing on the approach to breastfeeding (BF) and healthy complementary feeding (HCB). Qualitative research was used, with documentary analysis of pedagogical projects (PP), menus and teaching plans and semi-structured interviews with professors in the disciplines of Pediatric Dentistry and Orthodontics from six São Paulo colleges, from March to May 2018. The analyses showed that the PP are aligned with the NCG, but there is little approach aimed at BF and $\mathrm{HCB}$ as promoters of oral health. The study concluded that there were advances in the training of human resources in health based on a solid framework formed by Brazilian legislation. There are, however, challenges to be considered, and it is necessary to advance in the development of skills and competencies advocated by the NCG in themes that expand health promotion. Higher education institutions need to encourage the PP to take shape by training professionals in line with their proposals and the new demands of the health system.

Keywords: dentistry education; national curriculum guidelines; breastfeeding; complementary healthy feeding; health promotion. 